\title{
Relationship between the Development of Outer Hair Cell Electromotility and Efferent Innervation: A Study in Cultured Organ of Corti of Neonatal Gerbils
}

\author{
David Z. Z. He \\ Auditory Physiology Laboratory (The Hugh Knowles Center), Departments of Neurobiology and Physiology, and \\ Communication Sciences and Disorders, Northwestern University, Evanston, Illinois 60208
}

\begin{abstract}
Outer hair cell (OHC) electromotility, which powers the cochlear amplifier, develops at a later stage of hearing ontogeny. There has been speculation whether efferents play a necessary role in directing or achieving $\mathrm{OHC}$ maturation in mammals. In this study, we examine whether the development of $\mathrm{OHC}$ motility depends on the establishment of efferent innervation of the cells' synaptic pole by measuring electromotility of $\mathrm{OHCs}$ grown in cultures, deprived of efferent innervation. Tissue cultures of the organ of Corti were prepared from the cochleas of newborn gerbils. Solitary OHCs were obtained from 4- to 15d-old cultures by enzymatic digestion and mechanical tritura-
\end{abstract}

tion. Length changes evoked by transcellular electrical stimulation were detected and measured with a photodiode sensor. Results show that $\mathrm{OHCs}$ develop electromotility between 6 and $13 \mathrm{~d}$ in culture without the presence of efferent innervation. The timetable for the onset of $\mathrm{OHC}$ electromotility is comparable with that in vivo. This demonstrates that the ontogeny of $\mathrm{OHC}$ electromotility is an intrinsic process that does not require the influence of efferent innervation.

Key words: electromotility; outer hair cells; tissue culture; efferent; denervation; gerbil; development; neurotrophic effect
The interaction between peripheral nerve fibers and their target organs during development has been an interesting topic to neuroscientists since the observations of Cajal (1919), who first studied and discussed neurotrophic interactions during embryonic development. Speidel $(1947,1948,1964)$ reported in a series of articles that lateral-line sensory receptors in regenerating tails of the green frog tadpoles, rendered aneural by repeated sectioning of the regenerating lateral line nerves, could develop independent of any influence from their sensory nerves. Jörgensen and Flock (1976) extended the original observations of Speidel with ultrastructural observations of regenerating tail lateral-line tissue in salamander embryos. They showed that normal sensory hair cells with synaptic bodies could develop in the absence of their normally present sensory nerves. However, observations by Knowlton (1967), Orr (1968), Sher (1971), and Thornhill (1972) provided evidence supporting a relationship between the presence of neural elements and the cytodifferentiation of sensory cells.

$\mathrm{OHCs}$ can contract or elongate at acoustic frequencies upon direct electrical stimulation (Brownell, 1983; Brownell et al., 1985). This electromotility is believed to be a part of the feedback process that contributes to the exquisite frequency selectivity and sensitivity observed in the mature mammalian cochlea (Brownell et al., 1985; Dallos, 1992a). Although immotile at an earlier stage of development, OHCs acquire motile behavior at the later stage

Received July 22, 1996; revised Feb. 19, 1997; accepted Feb. 25, 1997.

This work was supported by National Institutes of Health Grant DC 00708 to Peter Dallos from the National Institute of Deafness and Other Communication Disorders. I thank Dr. Peter Dallos for support and comments on this manuscript, Brian Clark for programming, Drs. Xi Lin, Xintian Hu, Burt Evans, Tienchen Liu, and Gulam Emadi for technical assistance and Roxanne Edge and Malini Pearce for assisting with EMs.

Correspondence should be addressed to David Z. Z. He, Auditory Physiology Laboratory (The Hugh Knowles Center), Departments of Neurobiology and Physiology, and Communication Sciences and Disorders, Northwestern University, 2299 North Campus Drive, Evanston, IL 60208.

Copyright (C) 1997 Society for Neuroscience $0270-6474 / 97 / 173634-10 \$ 05.00 / 0$ of ontogeny (Pujol et al., 1991; He et al., 1994). In gerbil, OHCs develop electromotility between 7 and $12 \mathrm{~d}$ after birth (He et al., 1994).

In mature mammals, OHCs are innervated dominantly by efferents, which originate in the superior olivary complex. However, ultrastructural studies in developing gerbils show that in the first two postnatal days OHCs are exclusively innervated by afferents. During the next few days, efferent fibers approach OHCs (Pujol et al., 1978; Echteler, 1992) as the inappropriate connections of afferents to the OHC system withdraw. Labeling experiments in mouse and hamster indicate that efferent fibers contact OHCs 4-8 d after birth (Simmons et al., 1990; Sobkowicz, 1992).

There has been speculation whether efferents play a necessary role in directing or achieving $\mathrm{OHC}$ maturation in mammals. Whether the functional maturation of $\mathrm{OHCs}$, i.e., their major role as force-generating effectors via their electromotile mechanism, depends on the establishment of efferent innervation at their synaptic pole is still unknown. The present study attempts to address this question by determining whether $\mathrm{OHCs}$ isolated from efferent-deprived cultures of the organ of Corti develop motility as they normally do in developing animals.

Organotypic cultures of the organ of Corti of newborn gerbils were developed for the experiments. The gerbil offers several important advantages for the study of development and interaction between nerve fibers and hair cells. As in other altricial rodents such as rat, mouse, and hamster (Echteler, 1992), the onset of hearing in gerbil does not occur until at least $10 \mathrm{~d}$ after birth (Woolf and Ryan, 1984). Therefore, important periods of development in the auditory periphery that precede the onset of hearing are more amenable to direct observation in this animal than in precocial mammals (primates, cats, and guinea pigs) whose hearing begins prenatally or at birth (Rubel, 1978; Horner et al., 1987). 


\section{MATERIALS AND METHODS}

Births in the gerbil breeding colonies were monitored at 9 A.M. and 5 P.M. daily. Litters that were born during the daytime were used for cochlear explantation. Unless stated, explantations were performed on the same day when the litters were born. The day when the explantation was performed was designated as 0 day in vitro (DIV) and the next day as 1 DIV and so on.

Cochlear explantation. A detailed description of the general preparation, dissection, and culturing of the isolated organ of Corti of mouse is given by Sobkowicz et al. $(1975,1993)$. The method described below is simple but different from theirs, although the general preparation and dissection procedures are similar. Therefore, only differences are highlighted below.

Newborn gerbil pups were cryoanesthetized at $-10^{\circ} \mathrm{C}$ for $5 \mathrm{~min}$. After the skin was cleaned with $75 \%$ alcohol, the animals were decapitated. The head was then bisected midsagittally. After the skin was peeled off the scalp, the hemiskull was cut into two pieces posteriorly to the eye, and the piece containing the cochlea was kept in cold preoxygenated medium in a plastic Petri dish $(60 \times 15 \mathrm{~mm}$, Style, Falcon $)$. The medium used for dissection was Leibovitz's L-15 (Life Technologies, Grand Island, NY) supplemented with $15 \mathrm{~mm}$ HEPES and adjusted to $\mathrm{pH}$ 7.35, $300 \mathrm{mOsm}$.

Unlike the mature gerbil's cochlea, that of the newborn was very small and difficult to find. It was critical to identify appropriate landmarks. To find landmarks, the concave surface of the hemiskull should be oriented toward the investigator under an upright dissecting scope (Wild M5). After the muscles attached to the temporal bone were removed, a striking landmark, a half-turn white ring, the ossifying tympanic annulus, could be seen. After removing the tympanic annulus, one could see the inner ear cavity. The cochlea, which was a cartilaginous capsule at this stage, lay within this cavity filled with tenacious mesenchymal tissue. Once the cochlea was identified, the remaining tissues outside the inner ear cavity could be removed, and the cochlea was transferred to a new dish containing fresh medium.

The next maneuver was to open the wall of the cochlear capsule without disrupting the organ of Corti. One pair of fine forceps was used to hold the cochlea, and the cartilage of the capsule was carefully peeled off, piece by piece, from the oval window to the apex with another pair of fine forceps. At this point, the two and one-half turns of the organ of Corti bordered by the stria vascularis could be seen clearly. Two approaches were taken to dissect out the organ of Corti, depending on whether the spiral ganglion cells were to be kept with the tissue. To maintain afferent innervation, cuts were made between the mid and basal turns and between the mid and apical turns. To remove afferent innervation, the basilar membrane-organ of Corti was carefully unwrapped from the modiolus, where spiral ganglion cells resided. In both cases, the efferent innervation was eliminated. The organ of Corti from apical and basal turns was transferred to small size dishes $(35 \times 10 \mathrm{~mm}$, Style, Falcon) containing $0.85 \mathrm{ml}$ of DMEM (Life Technologies). It is important to maintain a thin layer of medium to allow adequate oxygen diffusion to the tissue. The tissue was pressed firmly but carefully onto the bottom of the dish with the Deiters' cell side lying on the bottom of the dish and the ciliated pole of hair cells pointing upward toward the experimenter. No collagen was used to coat the dish. After $\sim 2 \mathrm{hr}$ incubation, $150 \mu \mathrm{l}$ of heat-inactivated fetal bovine serum (Life Technologies) was added to each dish. Serum present in the media at the time of transplantation would prevent tissue from adhering to the bottom of the dish. The cultures were then left in a $37^{\circ} \mathrm{C}$ moist incubator (Lunaire, Lunaire Environmental, Inc.) with $5 \% \mathrm{CO}_{2}$ for in vitro growth. The culture medium was replaced every $2 \mathrm{~d}$. The color of the medium was monitored, and the cultures were taken out from the incubator for observation and photographing under an inverted tissue culture microscope (Leitz IL900), which was also equipped with fluorescence capability.

The entire dissection and explantation procedure was performed on a cold plate inside a laminar flow hood (EdgeCard Hood, Baker Company, Sanford, ME). Frequent rinsing of the specimen and changing of dishes during the dissection greatly reduced the chance of contamination. No antibiotics were added to the dissection and culture media.

Isolated hair cell preparation. After the tissue was cultured for a desired interval, the dish was taken out of the incubator and quickly rinsed in buffer to remove any excess protein. Enzymatic digestion medium [L-15 supplemented with $1 \%$ trypsin (Sigma, St. Louis, MO) and $1 \mathrm{mg} / \mathrm{ml}$ collagenase type IV (Sigma)] was then added to the dish. After $30 \mathrm{~min}$ incubation, the organ of Corti was transferred to the experimental bath containing fresh L-15 medium. To obtain solitary OHCs, gentle trituration of the tissue with a small pipette was needed. To compare the onset

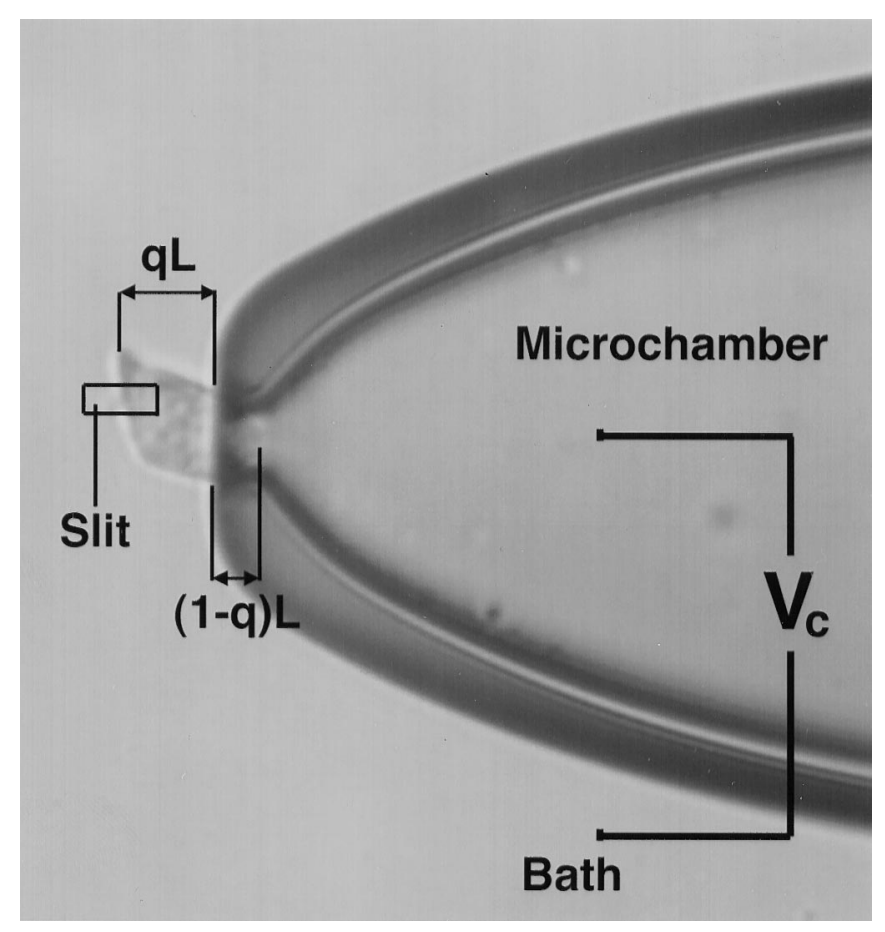

Figure 1. Video image showing experimental setup for measuring electromotility with the microchamber technique. An OHC (isolated from the basal turn of an 8-d-old gerbil cochlea) is $80 \%$ inserted into the microchamber with its synaptic pole inside. The culticular plate is imaged via rectangular slit on a photodiode. The photocurrent is proportional to length changes. Command voltage $\left(V_{c}\right)$ is delivered between electrolytes inside and surrounding the microchamber. The partitioning of the cell in the microchamber forms a voltage divider. The voltage drops on the included and excluded membrane segments are in opposite polarity and have approximate magnitudes of $q V_{\mathrm{c}}$ and $(1-q) V_{\mathrm{c}}$ (Dallos et al., 1993a,b), where $q$ is the fraction of the cell length outside microchamber (here $q=$ 0.75 ). The image is modified from an earlier publication (He et al., 1994).

time of electromotility, OHCs from developing gerbils with corresponding age were also isolated. Those cells were referred to as in vivo OHCs. Microchamber, experimental bath, and protocols. Detailed description of the experimental method and apparatus for motility measurement can be found elsewhere (Evans et al., 1991; He et al., 1994). It is recapitulated briefly.

Isolated OHCs were gently drawn partially into a microchamber (Fig. 1), which resembled, in principle, the suction pipette used by Baylor et al. (1979) for the study of isolated retinal rods. The microchamber was fabricated from $2 \mathrm{~mm}$ thin-wall glass tubing (Glass Company of America) by a two-stage microelectrode puller (Narishige) and heat-polished to an aperture diameter close to that of a hair cell $(\sim 8-9 \mu \mathrm{m})$. The microchamber, with a series resistance of $\sim 0.4-0.5 \mathrm{M} \Omega$, was mounted in an electrode holder that was held on a Leitz 3-D micromanipulator. The position and height of the microchamber in the bath were readily adjustable with the micromanipulator. By moving the microchamber, cells in the bath could be picked up easily. The experimental bath, which contained the solitary OHCs, was placed on the stage of an inverted microscope (Zeiss LM201). The bath was grounded via a $\mathrm{Ag} / \mathrm{AgCl}$ electrode. The microchamber was connected to the voltage command generator by a $\mathrm{Ag} / \mathrm{AgCl}$ wire. The suction port of the microchamber holder was connected to a micrometer-driven syringe to provide positive or negative pressure so as to draw in or expel the cells. The inserted cell and the microchamber formed a resistive seal $(4-6 \mathrm{M} \Omega)$ that was mechanically stable but allowed the cell to be moved in and out of the pipette without apparent damage to it. Cells were selected for experiments if they showed no obvious signs of damage and/or deterioration such as swelling, translocation of nucleus, and granulation.

Length change measurement and stimulus generation. A Zeiss inverted microscope with $10 \times, 16 \times$, and $40 \times$ objectives was used for the experiments. Cell motions were measured by the change in the current of a photodiode when the magnified image of the ciliated pole was projected 
Figure 2. Survey microphotograph of a 1-d-old culture of basilar membrane-organ of Corti prepared from basal turn cochlea of a newborn gerbil pup. The first outgrowth seen from the culture is the mesenchymal tissue emanating from the cut edges. The individual structural regions in the explanted tissue can be easily identified at this stage. The central core of the explant contains the spiral ganglion cells $(s g)$, which are surrounded and overlaid by loose mesenchymal tissue. Progressing outward radially from the central core lie the limbus $(l i)$, the epithelium of the inner spiral sulcus (is), the organ of Corti (arrows indicate the hair cell region), Hensen's cells, and an outgrowth zone emanating from the cut edge of the tissue. The microphotographs shown in this and in all subsequent figures were taken with an inverted microscope and brightfield illumination. Scale bar, $120 \mu \mathrm{m}$.

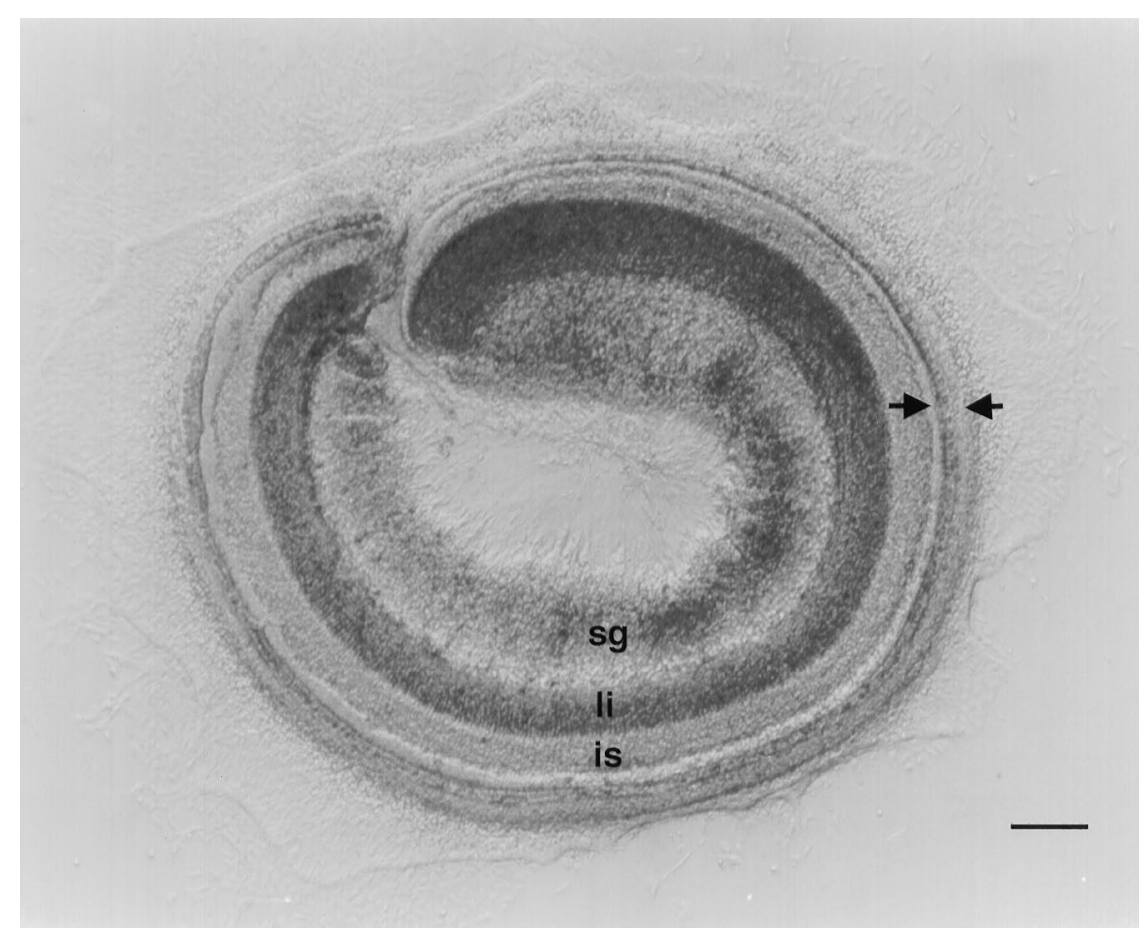

onto the photodiode through a rectangular slit (Fig. 1). The cell position in the slit was also monitored by a video camera behind the slit. The photocurrent response was calibrated to length change units by an optical lever method (Clark et al., 1990). The photodiode measurement system, without postfiltering, had a corner frequency ( $3 \mathrm{~dB}$ roll-off) of $1100 \mathrm{~Hz}$. After amplification, the photocurrent signal was low-pass-filtered at 1600 $\mathrm{Hz}$ by an antialiasing filter before being digitized by a Metrabyte DASH$16 \mathrm{~F}$ data acquisition board in a PC. The sampling frequency was $10 \mathrm{kHz}$. With some averaging, movement amplitudes as low as $10 \mathrm{~nm}$ could be routinely detected. In general, the results were the average of 100 presentations. Experiments were performed at room temperature (20 \pm $2^{\circ} \mathrm{C}$ ) and videotaped with a Panasonic video recorder.

The electrical stimulus was a sequence of $10 \mathrm{msec}$ rectangular pulses of alternating polarity separated by $40 \mathrm{msec}$, increasing in amplitude from \pm 40 to $\pm 280 \mathrm{mV}$ in $\pm 40 \mathrm{mV}$ steps (Fig. $7 \mathrm{f}$ ). The stimulus was generated by a programmable stimulus generator (Qua Tech) on a PC.

When the cell was partially inserted into the microchamber, the voltage command $V_{\mathrm{c}}$ was applied across the excluded and the included segments of the cell, which together formed a voltage divider. Therefore, the voltage drops on the included and excluded membrane segments were of opposite polarity and had approximate magnitudes of $q V_{\mathrm{c}}$ and $(1-q) V_{\mathrm{c}}$, where $q$ was the fraction of the cell length excluded from the chamber (Dallos et al., 1991). For example, if the cell was $80 \%$ excluded $(q=0.8)$ and the voltage command was varied from \pm 40 to $\pm 280 \mathrm{mV}$, the calculated voltage drop on the excluded segment was estimated to be approximately \pm 8 to $\pm 56 \mathrm{mV}$. The details of the modeling and calculations can be found elsewhere (Dallos et al., 1992b, 1993a,b).

Morphological examinations of the cultured organ of Corti. The development and condition of the cultures were routinely examined under an inverted microscope. Using Nomarski or Hoffmann optics, one could easily observe the "V"- or "W"-shaped stereocilia bundle on the cuticular plate of hair cells. Visualization of cilia was generally accepted as a way to identify hair cells and to assess their viability in tissue culture (Sobkowicz et al., 1975, 1993). It was not difficult to observe the cilia during the first 2-4 d of explantation, when the architectural organization of the explanted tissue was not yet disrupted. However, when different tissue constituents shifted in position because of proliferation and growth, the standard architecture of the organ of Corti was no longer retained and visualizing hair bundles became difficult. A live/dead EukoLight assay L-3224 (Molecular Probes, Eugene, OR) was used to assess viability of the cells (Haugland, 1992). When the cells were in good condition, cell outlines in yellow/green color could be seen. If the cells were dead, red nucleus was revealed. Because of the unique organization of the organ of Corti seen under a fluorescence microscope, this assay could actually help to identify hair cells when viewing stereocilia was no longer possible in the long-term cultures.

For morphological examination of the basilar membrane-organ of Corti, the cultures were quickly rinsed in buffer to remove excess medium and fixed for $1 \mathrm{hr}$ at room temperature with $5 \%$ glutaraldehyde in $0.1 \mathrm{M}$ sodium cacodylate buffer, $\mathrm{pH}$ 7.4, containing $1 \mathrm{~mm} \mathrm{CaCl} 2$. After a thorough buffer rinse, the cultures were post-fixed in $1 \%$ osmium tetroxide in $0.1 \mathrm{M}$ sodium cacodylate with $1 \mathrm{mM} \mathrm{CaCl}$ for $10 \mathrm{~min}$. Dehydrated in acetone, the tissues were embedded in a mixture of Araldite and Epon 812 in flat rubber molds. The blocks were then mounted in an Ultracut (AO/Reichert, Buffalo, NY). Two micrometer semithin sections were cut with a glass knife and stained with $1 \%$ Toluidine blue in $0.5 \%$ borax buffer and photographed. For electron microscopic examination, $60 \mathrm{~nm}$ thin sections were cut with a diamond knife and collected on 300-mesh grids or Formvar-coated slot grids. Stained with 3\% uranyl acetate for 15 min and $1.5 \%$ lead citrate for $3 \mathrm{~min}$, the preparations were examined in an electron microscope (JEOL 100CX) and photographed.

The sensory organ can be excised either with or without its complement of spiral ganglion. To verify whether the cochlear ganglion cells were present in the cultures, anti-neurofilament immunohistochemical staining was used to label the ganglion cells. Cultures were fixed for $1 \mathrm{hr}$ with $4 \%$ paraformaldehyde prepared in $0.1 \mathrm{M}$ PBS, $\mathrm{pH}$ 7.3. The tissues were then incubated with an anti-neurofilament antibody (mouse monoclonal, 160 $\mathrm{kDa}$, Sigma) for $24 \mathrm{hr}$ at $4^{\circ} \mathrm{C}$. The antibody was diluted from the stock (1:100) in a solution containing $20 \%$ fetal calf serum, $80 \%$ PBS, $0.02 \%$ Triton X-100, and $0.05 \%$ thimerosal. After being stained with the primary antibody, the cultures were rinsed with PBS three times before being labeled with a secondary antibody for $2 \mathrm{hr}$ at room temperature $(20 \pm$ $2^{\circ} \mathrm{C}$ ). The secondary antibody (Sigma) was an anti-mouse IgG conjugated with FITC. Explants were washed twice with PBS and mounted on an inverted microscope with fluorescence capability for photographing.

\section{RESULTS}

\section{Morphology of the cultures}

Figure 2 shows a survey micrograph of a typical 1-d-old culture of basilar membrane-organ of Corti prepared from the basal turn of a newborn gerbil. The basilar membrane-organ of Corti is the fastest growing tissue and, after attaching to the substrate, grows luxuriantly. First outgrowth, which is easy to see even after a few hours of explantation, is the mesenchymal tissue emanating from the cut edges of the tissue. Another indication of growth is the 


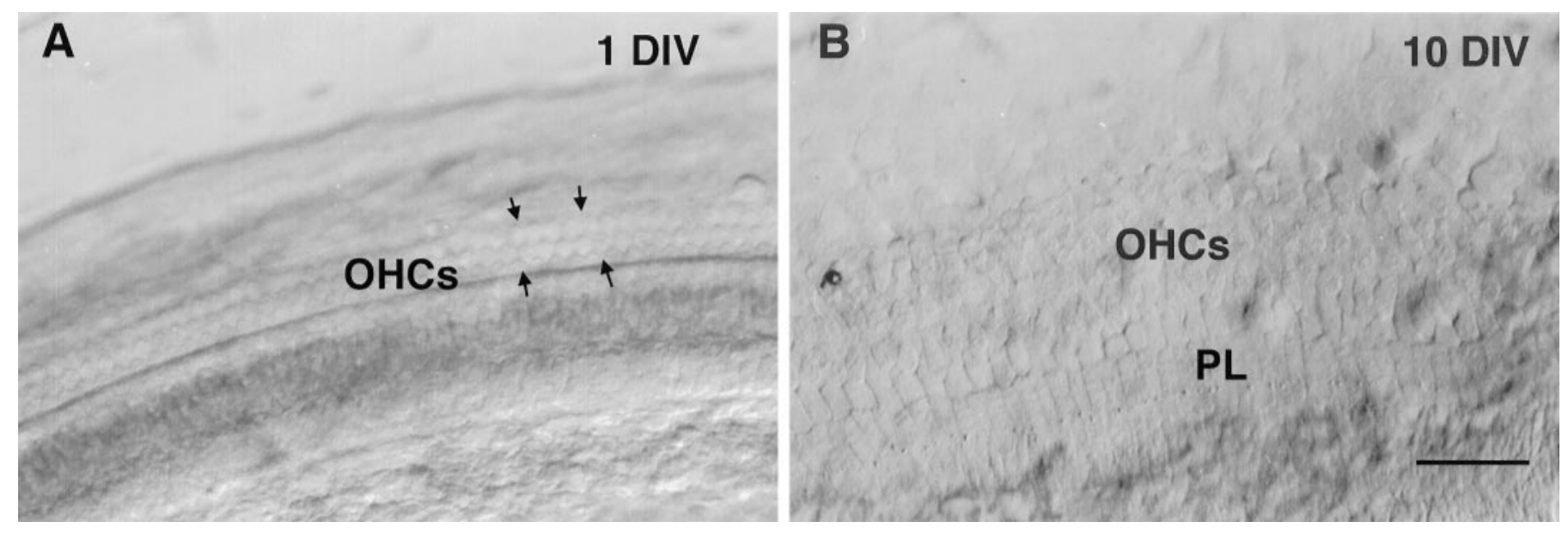

Figure 3. A, Surface view of the hair cell region of a live 1-d-old culture. The culture was prepared from the basal turn of a newborn gerbil cochlea. Three rows of the "V"-shaped stereocilia identify the OHCs. Inner hair cell stereocilia are partially obscured. At this stage, the organization of the organ of Corti is well maintained as manifested by alignment of three rows of OHCs and one row of IHCs. $B$, Surface view of the hair cell region of a live 10-d-old basal turn cochlear culture. It is very difficult to see hair bundles at this stage. The elongated bodies are pillar cells (Pi). Scale bar, $50 \mu \mathrm{m}$ (for both panels). Hoffmann modulation contrast optics were used.

expansion of the structural regions caused by the growth of the constituent cells. The individual structural regions in the explanted tissue can be identified. The central core of the explant contains the spiral ganglion cells, which are surrounded and overlaid by loose mesenchymal tissue. Progressing outward radially from the central core lie the limbus, the epithelium of the inner spiral sulcus, the organ of Corti (marked by arrows in Fig. 2), Hensen's cells, and an outgrowth zone emanating from the cut edge of the tissue. Figure $3 A$ shows a top view of the hair cell region using Hoffmann optics. The three rows of $\mathrm{V}$-shaped structures indicate the hair bundles of OHCs. The outlines of the elongated bodies are the pillars. The cilia of inner hair cells are partially obscured.

As an example, Figure $4 A$ depicts a fluorescence image of a hair cell region obtained from the same preparation as shown in Figure $3 A$ with the live/dead two-color assay. Whereas the yellow/ green color signifies the integrity of the hair cells, the alignment of OHCs manifested in the fluorescence image indicates that the organization of the organ of Corti is well maintained at this stage. Over the next several days, the individual structural regions expanded dramatically and their boundaries became less clear. The tissue was flattened out, and more mesenchymal tissue was seen along the cut edges. Under high magnification, it is apparent that the architectural organization of the organ of Corti was disturbed because of the growth and shift of different tissue constituents. It may be that because the stria vascularis, the formidable wall that could block the spread of the explant and retain the architecture of the organ, was removed before explantation, disorganization of the hair cell region occurred (Sobkowicz et al., 1993). The shift and collapse of the tissue made the hair bundles difficult to view. It is difficult to identify hair cells in Figure $3 B$, which was obtained from a 10-d-old culture. However, if the hair cells were labeled with the two-color fluorescence-based assay, one can easily identify them by their unique arrangement, i.e., one row of IHCs and three to four rows of OHCs as shown in Figure $4 \mathrm{~B}$. It is not uncommon to see more than three rows of OHCs in the late stage of culturing. Generally, the explanted organ of Corti can grow in culture for $>16-18 \mathrm{~d}$. However, at the later stage, i.e., after $\sim 12-14 \mathrm{~d}$, deterioration can occur, as reflected by a loss in hair cells in some areas.
In most of the cultures, afferent innervation was preserved. One way to confirm this was to use anti-neurofilament immunohistochemical staining to label the ganglion cells. Figure 4, $C$ and $D$, presents images of immunofluorescent staining of ganglion cells from a 10-d-old culture of the organ of Corti. As shown, spiral ganglion cells are located in the central core of the explant and give rise to radial fibers innervating the organ of Corti (Fig. 4C). In the hair cell region, outer spiral fibers are also seen. One interesting observation is that some afferent neurons project radially and innervate both IHCs and OHCs (arrows in Fig. 4D). Similar observations at the apex of newborn gerbils (Echteler, 1992) and a newborn cat (Perkins and Morest, 1975) were reported previously. One might notice the low density of spiral ganglion cells and radial fibers in the culture. It is quite common that only a fraction of the spiral ganglion cells survives in the tissue culture (Sobkowicz et al., 1993). Surgical trauma and culture environment are usually responsible for this.

Figure 5 shows radial sections of the basilar membrane obtained from 2- and 10-d-old cultures. Some gross morphological features are illustrated clearly in the survey pictures. The most important feature is that hair cells and supporting cells are closely packed and that no extracellular space is found at 2 DIV. Tunnel of Corti at this stage is still not formed. At $10 \mathrm{DIV}$, the tunnel of Corti is already formed and the Nuel's spaces between outer hair cells start to open. In developing gerbils, the tunnel of Corti is formed between 6 and $8 \mathrm{DAB}$ and extracellular spaces begin to appear after 8 DAB (Souter et al., 1995). The appearance of tunnel of Corti and Nuel's space in cultured tissue is clearly comparable with that in intact gerbils. One might also notice that the height of basilar membrane at 2 DIV is greater. As development progresses, the thickness decreases. A decrease in basilar membrane thickness during development in gerbils is reported by Echteler (1995) and Schweitzer et al. (1996).

EM was used to examine the ultrastructure of the cultured hair cells and to verify their innervation. Six basal turn cultures (3 cultures with afferent and 3 without afferent innervation) were prepared for the EM examination. Each culture (block) was cut into four segments. When the appropriate location was found with $2 \mu \mathrm{m}$ survey sections, a series of $\sim 50$ consecutive thin sections (60 $\mathrm{nm})$ was cut from each segment. Figure 6 shows some represen- 

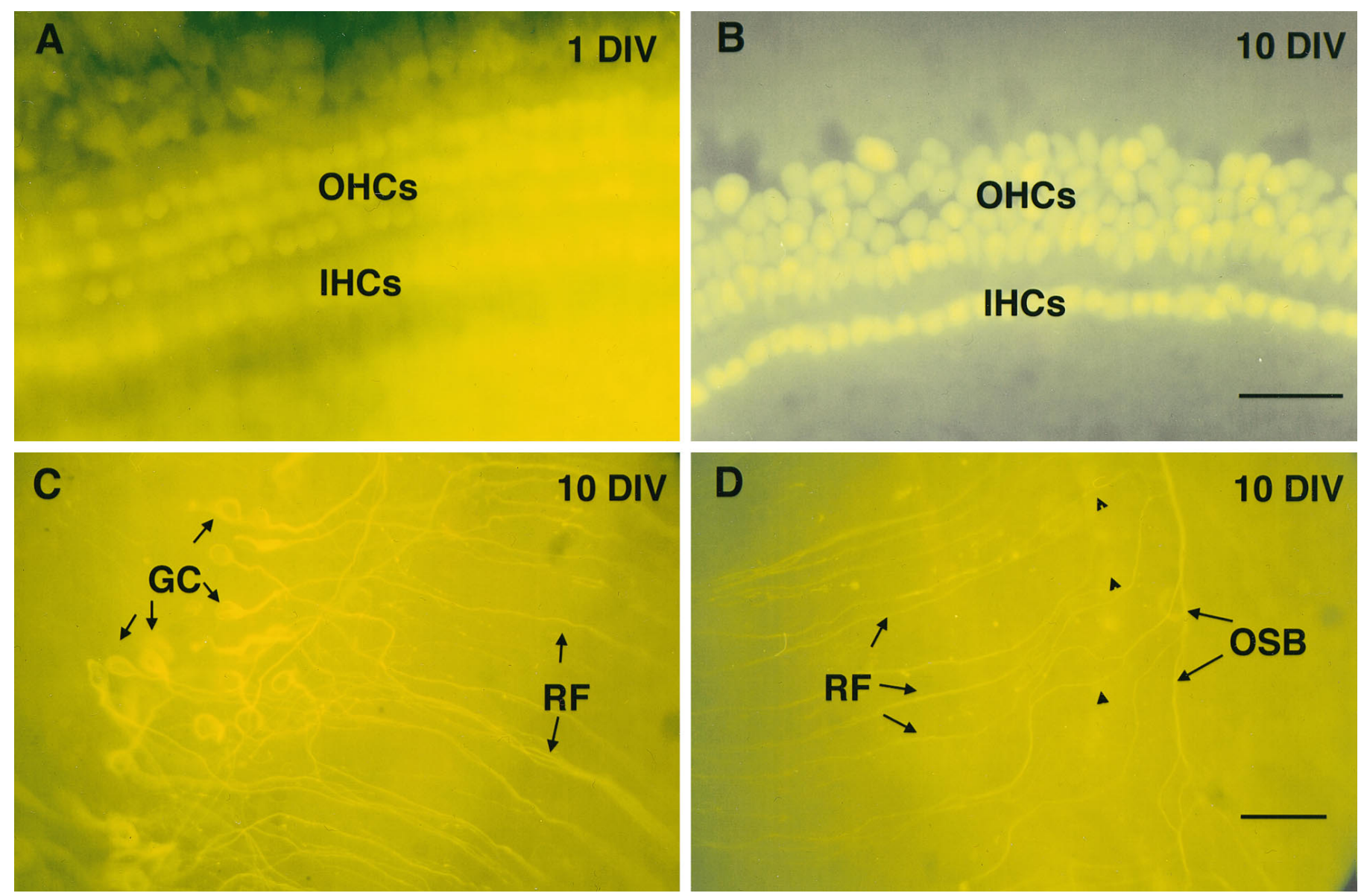

Figure 4. Fluorescence images of the cultured organ of Corti and spiral ganglion cells. $A, B$, A live/dead EukoLight assay L-3224 (Molecular Probes) was used to assess viability of the cells. When the cells are in good condition, cell outlines in yellow/green color can be seen. $A$, Fluorescence image of the same hair cell region shown in Figure $3 A$. The architectural organization of the organ of Corti at this stage is not yet disrupted, as evidenced by the well aligned three rows of OHCs and one row of IHCs. $B$, Fluorescence image of the hair cell region shown in Figure $3 B$. Note one row of IHCs and three to four rows of OHCs. The alignment of hair cells is irregular, indicating that organization of the organ of Corti is disrupted at this stage. Scale bar, 50 $\mu \mathrm{m}$ (for both $A$ and $B$ ). $C, D$, Fluorescence images of spiral ganglion cells in a 10-d-old culture of the basilar membrane-organ of Corti of a newborn gerbil. The ganglion cells labeled with an anti-neurofilament antibody are in yellow/green color when the secondary antibody (anti-mouse IgG) is conjugated with FITC. $C$, Ganglion cells $(G C$, arrows) lay in the central core of the culture and gave rise to radial fibers $(R F)$ innervating hair cells. Neurons are monopolar with a process projecting toward the receptor region. $D$, In the hair cell region, one can clearly see that some radial fibers joining outer spiral bundles (OSB, arrows) after innervating IHCs (arrows). Scale bar, $50 \mu \mathrm{m}$ (for both $C$ and $D$ ).

tative EM pictures taken from 10-d-old cultures with and without afferent innervation. In all sections examined, the ultrastructure of the cultured hair cells appeared to be normal and very similar to their in vivo counterparts. Cell organelles such as mitochondria, nucleus, and nucleolus could be seen clearly. The nucleus was always found close to the bottom of the cells, whereas the mitochondria were found in two major groups: the supranuclear and the infranuclear. When afferent innervation was removed, no afferent synapses were found, as shown in Figure $6 A$. Figure $6 B$ gives a magnified picture of the basolateral membrane of the cell shown in Figure $6 A$. One notices that one to two layers of subsurface cisternae are evident along the basolateral membrane at $10 \mathrm{DIV}$. This is an another important sign of growth because subsurface cisternae are virtually absent in newborn gerbil OHCs and do not appear until 8-10 DAB (Souter et al., 1995). For those cultures in which afferent innervation was maintained, afferent synapses could often be seen. Figure $6 C$ shows an example of two afferents making synapses with an $\mathrm{OHC}$. The presynaptic dense bodies are marked with arrows.

\section{Onset of $\mathrm{OHC}$ electromotility}

To determine whether and when the cells became motile, solitary OHCs obtained from age-graded tissue cultures of the organ of Corti were partially drawn into the microchamber with $\sim 20 \%$ of their length inserted. Square-pulse voltage commands with opposite polarity and increasing amplitude were applied, and length changes of the excluded segment (ciliated pole) were measured. Motile response is defined as any measurable change in length that is repeatable and time-locked to the stimulus. As an example, Figure 7 shows the responses of some OHCs isolated from 5- to 10-d-old cultured cochleas. No motile response could be detected at any voltage level at 5 DIV, as shown in Figure $7 a$. However, at 7 DIV, some motile responses (Fig. $7 b$ ) could be observed at high command voltage level (above $\pm 200 \mathrm{mV}$ ). For a cell isolated from an 8 DIV cochlea, motile response (Fig. 7c) could be seen even at the lowest voltage level applied $(40 \mathrm{mV})$. For control purposes, inner hair cells encountered in the preparations were also drawn into the microchamber to measure motility. None of them revealed any 

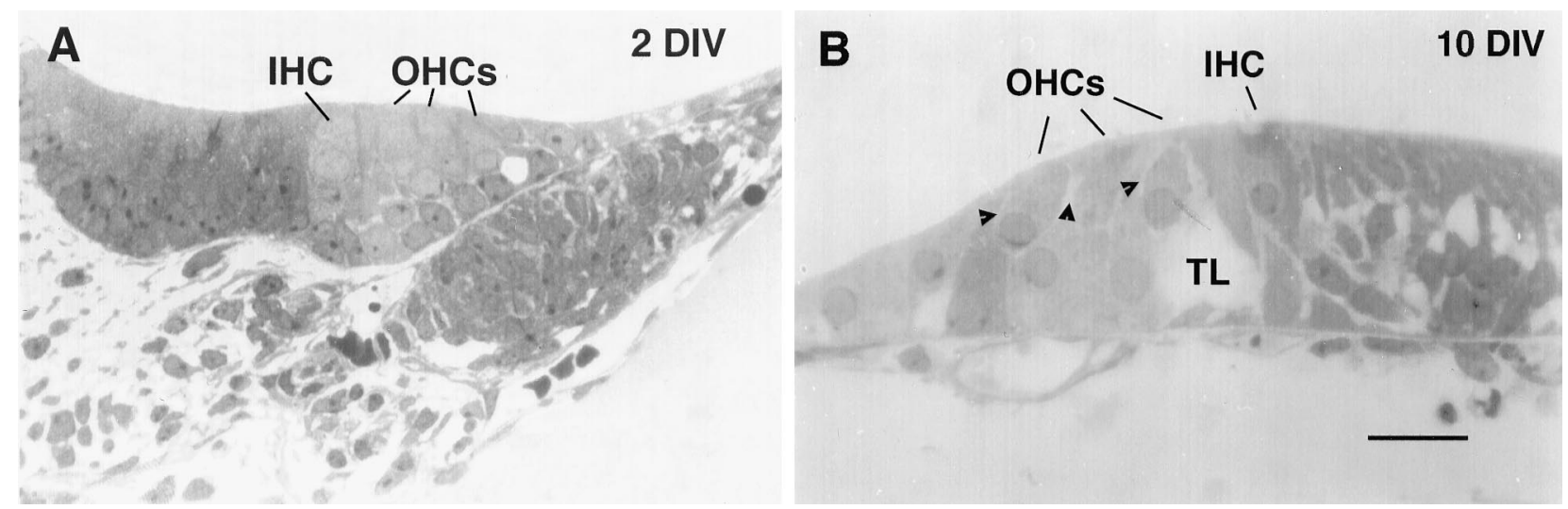

Figure 5. Radial sections of the basilar membrane and organ of Corti obtained from 2 and 10 DIV cultures (basal turn). A, Two DIV. Hair cells and supporting cells are closely packed; no extracellular space is found. Tunnel of Corti at this stage is not formed. $B$, Ten DIV. Note that the tunnel of Corti $(T L)$ is already formed and Nuel's spaces (arrows) begin to appear. The apical surface of the inner and outer hair cells displays stereocilia. The radial sections were obtained with standard EM procedures. The sections were $\sim 2 \mu \mathrm{m}$ in thickness and stained with $1 \%$ Toluidine blue. Arrows indicate Nuel's space. Bright-field illumination was used. Scale bar, $50 \mu \mathrm{m}$.

motile response. An example of the lack of responses of an inner hair cell (10 DIV) is plotted in Figure $7 e$.

The detailed timetable of the onset of electromotility at different ages is shown in Table 1. To determine whether there was a difference in onset of electromotility between apical and basal turn OHCs in cultures, OHCs from these turns were isolated and measured separately. Electromotility was first examined in 14 basal turn and 13 apical turn OHCs at 4 DIV. None of them at this age responded to any level of the electrical stimulation used in the experiments. Similarly, no motile responses were detected at 5 DIV. At 6 DIV, 1 of 13 basal turn OHCs exhibited detectable stimulation-following response, whereas 0 of 14 apical turn cells showed any motile response. Apical turn OHCs did not show motile response until 8 DIV. Over the next several in vitro days, the number of motile responsive cells increased in both turns. By 13 DIV, all of the OHCs tested were motile.

Figure 8 illustrates the percentage of motile cells (motile cells vs total cells measured) as a function of postnatal ages for the basal and apical turn OHCs. The percentage of motile OHCs measured from developing gerbils is also plotted for comparison. Interestingly, the onset of motility of the cultured basal turn cells precedes that of the in vivo cells, whereas the full expression of motility in the cultured apical and basal turn cells is delayed by $1 \mathrm{~d}$. When the onset of motility was compared between the cultured and in vivo cells between 6 and $13 \mathrm{DAB}$, statistical significance $(p \leq 0.05)$ was found between the two groups. It is not surprising that difference exists between the two groups of the cells because the organ of Corti often develop faster at the first few days in culture (Van de Water and Rubin, 1973; Van de Water et al., 1973; Sobkowicz et al., 1993) and then slows down at the later stage. As the base-apex gradient found in in vivo OHCs, electromotility appears in the cultured basal turn OHCs $2 \mathrm{~d}$ earlier than their apical turn counterpart.

All of the above data were collected from cultures with ganglion cells. To determine whether the early afferent innervation in OHCs would influence the development of motility, cochlear spiral ganglion cells were removed at the time of explantation. The absence of ganglion cells was verified by the negative staining results of anti-neurofilament labeling in six afferent-deprived cultures and by EM examination in four cochleas at $10 \mathrm{~d}$ (one example of the absence of afferent synapses is shown in Fig. 6A). Six afferent-present cultures were used to verify the presence of spiral ganglion cells at $10 \mathrm{DIV}$, and all of them showed positive staining (Fig. 4C,D). Another two afferent-present cultures were used for EM examination, and one example is given in Figure $6 C$. OHCs were isolated from afferent-deprived basal turn cochleas at $10 \mathrm{DIV}$, and the expression of motility was compared with that of OHCs isolated from afferent-present basal turn cultures at the same age. The percentage of motile responsive cells from afferent-deprived cultures was $64 \%$ (7/11 cells), whereas that of the afferent-present group was $69 \%$ (9/13 cells). No statistical significance was found between the groups $(p>0.05)$.

\section{DISCUSSION}

Tissue culture of the basilar membrane-organ of Corti

Tissue cultures of the cochleas of mouse (Van de Water and Ruben, 1971; Sobkowicz et al., 1975), rat (Lefebvre et al., 1990), guinea pig (Yamashita and Vosteen, 1975), and cat (Sugahara, 1964) have been reported, but no literature on tissue culture of the organ of Corti of gerbil is available. The development of such preparation can be useful in studying auditory development, neurotrophic effects, and hair cell regeneration.

The general morphology of the tissue culture of the organ of Corti of gerbils is not significantly different from that of mouse and rat. Hair cells in the cultures of this study can live for $>16-18$ d. All signs indicate that the explanted organ of Corti continues to grow. One obvious sign of growth in gross morphology is the formation of the tunnel of Corti and emergence of Nuel's space. At the ultrastructural level, the appearance of the cisternal layers along the plasma membrane is particularly important, because the formation of a first layer of laminated cisternae is found to be temporally coincident with the onset of motility in fetal guinea pig (Pujol et al., 1991) and at least one layer is required for the optimal generation of electromotility in mammalian OHCs (Holley and Ashmore, 1990; Pujol et al., 1991).

In the present studies, I did not measure the physiological condition (e.g., membrane potentials) of cultured cells. However, intracellular recordings by Russell et al. (1986a,b) from cultured mouse hair cells revealed that OHCs were only slightly depolarized in cultures (membrane potentials were approximately -57 $\mathrm{mV}$ ). The membrane potentials of IHCs and nonsensory supporting cells were also comparable with those of in vivo cells. It can be inferred from their studies that the physiological condition of hair cells in tissue culture environment is well maintained. 

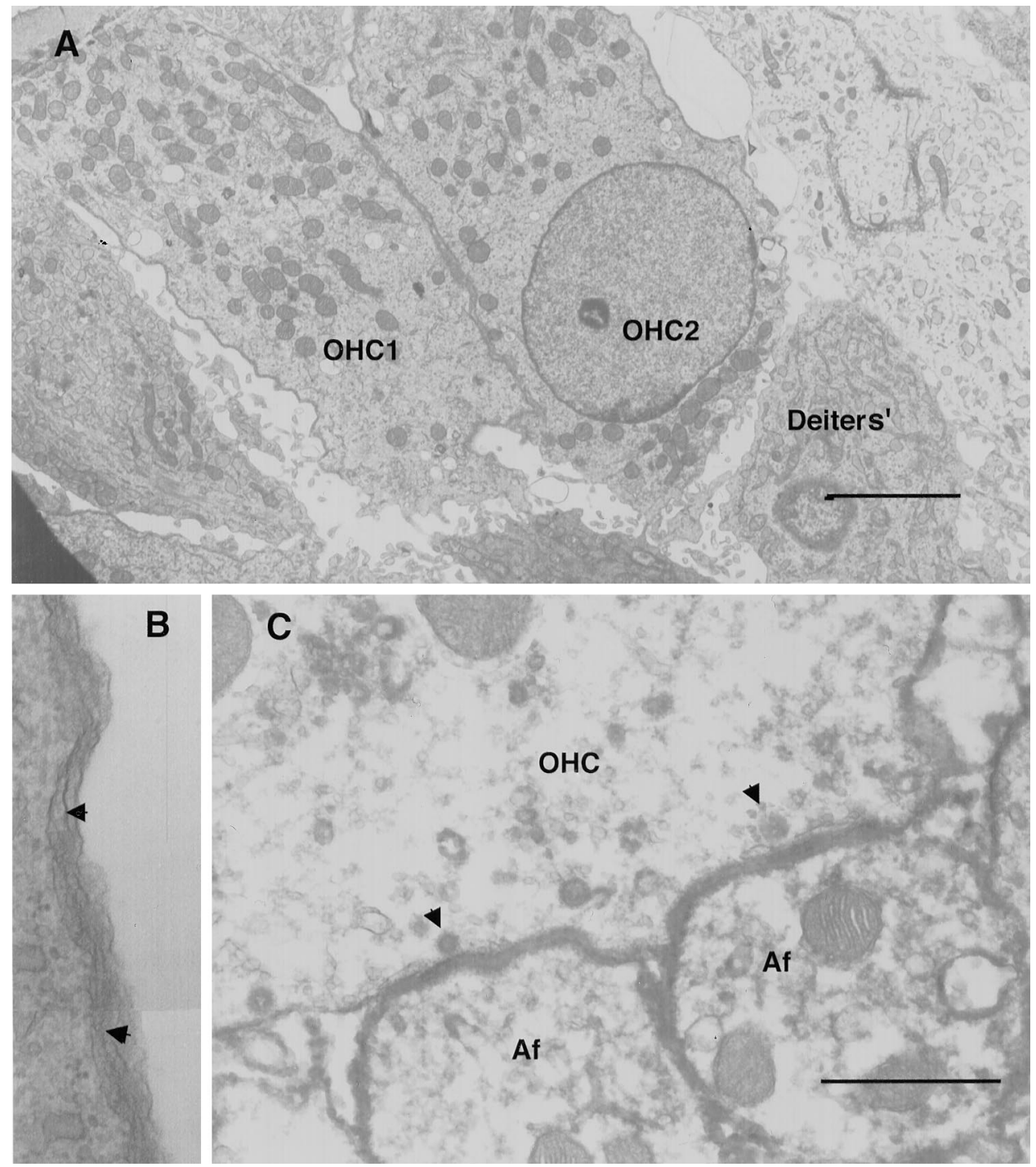

Figure 6. Electron microscopic pictures of 10-d-old OHCs. A, Ultrastructure of two OHCs obtained from an afferent-deprived culture. Cell organelles such as mitochondria, nucleus, and nucleolus are clearly shown. The nucleus is close to the bottom of the cells, and the mitochondria are found in two major groups: the supranuclear and the infranuclear. Note that no afferent innervation is present at the synaptic pole of the cell. Scale bar, $5 \mu \mathrm{m}$. $B$, An area of the basolateral membrane of the cell shown in $A$. Note that one layer of subsurface cisternea is present (arrows). $C$, OHC synaptic region with afferent innervation. Afferent synapses are marked with Af. Arrows indicate presynaptic ribbon. Scale bar, $1.5 \mu \mathrm{m}$.

\section{Ontogeny of OHC motility does not require neurotrophic effects of innervation}

Almost all previous studies on interaction between target sensory cells and their innervation focused on whether the sensory cells or the neurons could survive without the presence of one another and what were the morphological changes after denervation (Ard et al., 1985; Zhou and Van de Water, 1987; Hauger et al., 1989; Lefebvre et al., 1990). A number of investigations were also targeted to the question of how the presence of neuronal elements or the pattern of innervation exert influence on the cytodifferentiation of sensory cells (Knowlton, 1967; Orr, 1968; Sher, 1971; Thornhill, 1972; Van de Water, 1976, 1986, 1988; Van de Water et al., 1984, 1989; Pirvola et al., 1991). No attempt has been made to test directly the hypothesis that efferent innervation regulates the maturation of OHCs. There were some observations supporting this hypothesis. For instance, Kikuchi and Hilding (1965) noticed the delayed development of the organ of Corti and the early degeneration of OHCs in the Shaker-1 strain of mice, whose efferent innervation was virtually absent. Milkaelian and Ruben (1964) also reported that the appearance of cochlear potentials recorded from the Shaker-1 strain of mice was delayed when compared with normal animals. However, other studies seem to indicate that outer hair cell maturation is independent of efferent innervation. For example, when the efferent bundle is sectioned in 1-week-old kittens, OHCs appear normal in the adult cochlea but are covered exclusively with afferent terminals (Pujol and Carlier, 1982).

By examining the development of motility in OHCs from gerbil cochleas grown in vitro from the day of birth until $15 \mathrm{DAB}$, the present study shows that OHCs develop electromotility independent of efferent innervation. The appearance and maturation of motility are comparable with those of OHCs obtained from normally developing animals. The evidence is conclusive that efferent-denervated OHCs can develop motility with no significant delay. The ontogeny of OHC motility, therefore, seems to be essentially autonomous and likely governed by intrinsic local 


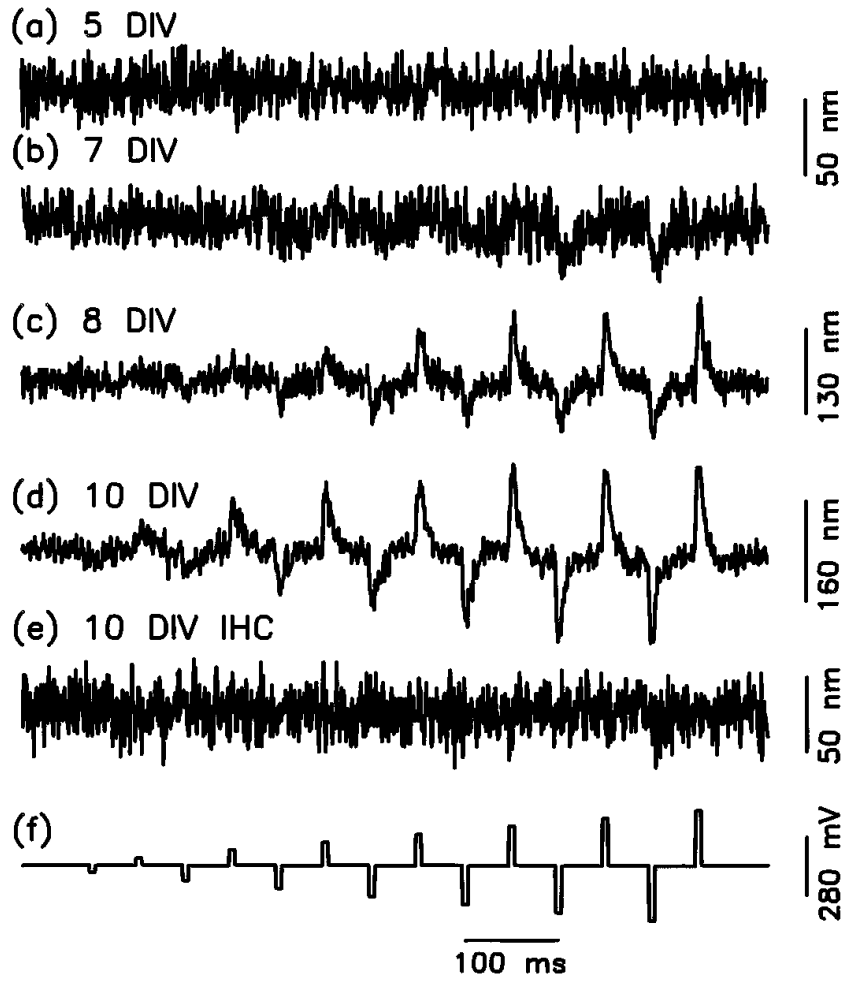

Figure 7. Motile responses and voltage command waveform. $a$, The noise floor with no detectable motile response at any levels. This trace was obtained from a $17-\mu \mathrm{m}$-long OHC harvested from the basal turn of a 5-d-old culture. $b$, Motile response of a 19- $\mu$ m-long $\mathrm{OHC}$ isolated from the basal turn of a 7-d-old culture. The motile response was observed above $240 \mathrm{mV}$ levels. $c$, Motile response of a $21 \mu \mathrm{m}$ OHC obtained from the basal turn of an 8-d-old culture. The response was seen at the lowest level $(40 \mathrm{mV}) . d$, Response of a $21 \mu \mathrm{m}$ OHC isolated from the basal turn of a 10-d-old culture. $e$, Response of an IHC obtained from the basal turn of a 10-d-old culture. No motile response was detectable at any level applied. $f$, Waveform of the square-pulse voltage command. The stimulus consisted of a sequence of $10 \mathrm{msec}$ rectangular pulses of alternating polarity separated by $40 \mathrm{msec}$, increasing in amplitude from \pm 40 to \pm 280 $\mathrm{mV}$ in $\pm 40 \mathrm{mV}$ steps. Cell contraction is plotted downward, and all of the responses are the average of 100 trials.

factors. Efferent denervation neither hinders nor alters the full expression of motility.

It needs to be emphasized that, in gerbils, it is not exactly clear when efferent fibers make contact with OHCs during develop-

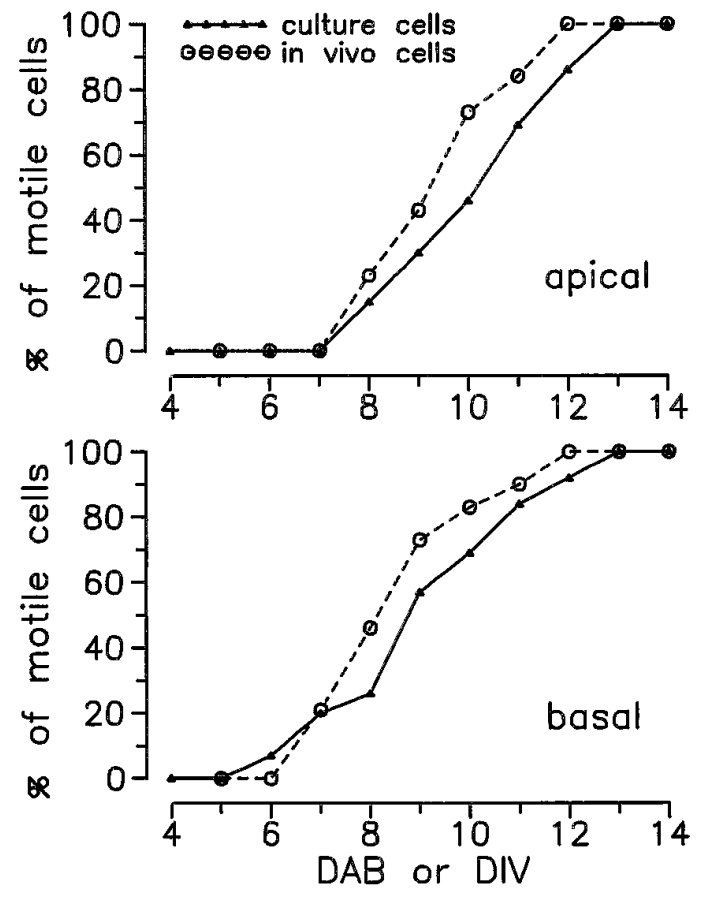

Figure 8. Percentage of motile cells obtained from cultured and in vivo cochleas at different ages. The percentage of motile cells was calculated as the number of motile cells versus the total number of cells tested at each age group. The number of motile cells and total cells tested is given in Table 1.

ment. The timing of the efferent innervation could be inferred from the mouse and hamster, whose onset of auditory function is very similar to that of the gerbil. Using Karnoversusky and Roots enzymatic staining, Sobkowicz and Emmerling (1989) showed that AChE-positive innervation occurs in outer hair cells between 3 and $7 \mathrm{~d}$ after birth in the base and between 7 and $10 \mathrm{~d}$ after birth in the apex of mouse cochleas. A similar time course of efferent innervation was also observed by Cole and Robertson (1992) and Merchan-Perez et al. (1994) in rat. In vitro horseradish peroxidase labeling in the developing hamster shows that efferent fibers contact OHCs between 6 and $8 \mathrm{~d}$ after birth (Simmons et al., 1990). Therefore, it is assumed that the efferent innervation of OHCs arrives $\sim 4-10 \mathrm{~d}$ in the gerbil.

Because the IHCs and OHCs receive separate and highly dis-

\begin{tabular}{|c|c|c|c|c|}
\hline $\begin{array}{l}\text { Age (DIV } \\
\text { or DAB) }\end{array}$ & $\begin{array}{l}\text { Motile cells } \\
\text { (cultured, basal) (\%) }\end{array}$ & $\begin{array}{l}\text { Motile cells } \\
\text { (cultured, apical) (\%) }\end{array}$ & $\begin{array}{l}\text { Motile cells } \\
\text { (in vivo, basal) }(\%)\end{array}$ & $\begin{array}{l}\text { Motile cells } \\
\text { (in vivo, apical) (\%) }\end{array}$ \\
\hline 4 & $0 / 14(0 \%)$ & $0 / 13(0 \%)$ & & \\
\hline 5 & $0 / 13(0 \%)$ & $0 / 13(0 \%)$ & $0 / 13(0 \%)$ & $0 / 12(0 \%)$ \\
\hline 6 & $1 / 13(7 \%)$ & $0 / 14(0 \%)$ & $0 / 11(0 \%)$ & $0 / 8(0 \%)$ \\
\hline 7 & $3 / 15(20 \%)$ & $0 / 14(0 \%)$ & $3 / 14(21 \%)$ & $0 / 11(0 \%)$ \\
\hline 8 & $4 / 15(26 \%)$ & $2 / 13(15 \%)$ & $6 / 13(46 \%)$ & $3 / 13(23 \%)$ \\
\hline 9 & $8 / 14(57 \%)$ & $4 / 13(30 \%)$ & $11 / 15(73 \%)$ & $6 / 14(43 \%)$ \\
\hline 10 & $9 / 13(69 \%)$ & $6 / 13(46 \%)$ & $10 / 12(83 \%)$ & $11 / 15(73 \%)$ \\
\hline 11 & $11 / 13(84 \%)$ & $9 / 13(69 \%)$ & $9 / 10(90 \%)$ & $11 / 13(84 \%)$ \\
\hline 12 & $13 / 14(92 \%)$ & $12 / 14(86 \%)$ & $10 / 10(100 \%)$ & $11 / 11(100 \%)$ \\
\hline 13 & $13 / 13(100 \%)$ & $13 / 13(100 \%)$ & $12 / 12(100 \%)$ & $13 / 13(100 \%)$ \\
\hline 14 & $14 / 14(100 \%)$ & $13 / 13(100 \%)$ & $10 / 10(100 \%)$ & $10 / 10(100 \%)$ \\
\hline
\end{tabular}

Note: Motility is defined as any measurable change in length at any level that is repeatable and time-locked with the stimulus. All cultures began on the day of birth. 
tinctive patterns of innervation, one might suspect that it is the difference in innervation that makes IHCs and OHCs develop differently and produce different physiological functions and properties. Such speculation is not totally without merit. An example of how innervation controls its target cells can be found in the interaction between muscles and their innervation (Close, 1965). In the auditory system, it was proposed that the presence of neuronal elements or the pattern of innervation exerted influence on the cytodifferentiation of sensory cells. Observations by Orr (1968) provided evidence supporting such a relationship. However, Van de Water and Rubin (1973) and Van de Water et al. (1973) demonstrated that inner ear sensory structures that formed in organ-cultured mouse otocysts were not dependent on trophic influence of neuronal elements for their development and differentiation (Van de Water, 1976, 1988; Van de Water et al., 1989). In our case, if it were the innervation that determined the characteristics of hair cells, one would have observed IHC motility at an early stage of development when IHCs were innervated by both afferent and efferent fibers. The immotility of IHCs demonstrated in this study suggests that it is not the difference in innervations that makes the two types of hair cells develop differently.

Although no significant difference in onset of electromotility was found between $\mathrm{OHCs}$ grown with and without spiral ganglion cells, the interpretation of the results needs to be made with caution. One reason is that we do not know precisely when afferents make contact with OHCs. Afferent innervation in some locations is already present at birth (Echteler, 1992). Therefore, it is difficult to rule out that early innervation can have any influence in hair cell development. However, this study at least demonstrates that removal of afferent innervation at birth does not hinder further development of OHCs. A similar conclusion was also reached by Sobkowicz et al. (1986), who demonstrated that removal of afferent innervation at birth did not hinder further morphological development of hair cells or cause any degeneration of the organ of Corti in tissue culture.

\section{Base-apex gradient of maturation of OHC motility in culture}

It is generally agreed that the organ of Corti develops in the basal turn first and that maturation then proceeds toward the apex (Lim and Anniko, 1985). In the developing animals, a great deal has been learned both morphologically and physiologically about the maturation difference between apex and base (for review, see Ryan and Woolf, 1992; Walsh and Romand, 1992). Although little is known about the base-apex gradient in maturation during development in vitro, determining whether such a gradient exists in cultured cells would help to determine whether the gradient is inherent or controlled by the surrounding environment.

Furness et al. (1989) studied the gradient of hair bundle morphology in cultured mouse cochleas. They demonstrated that the $\mathrm{OHC}$ stereociliary bundles showed a progressive change in differentiation from apex to base. The degree of differentiation at apical and basal locations was comparable with that in vivo. The present study shows that the onset of electromotility occurs in the basal turn OHCs first and follows by the apical cells with a $2 \mathrm{~d}$ delay. In developing gerbils in vivo, there is a $1 \mathrm{~d}$ difference in onset of motility between the basal and apical turn cells (He et al., 1994). Although difference exists between in vivo and cultured OHCs in motility onset, the presence of a base-apex gradient in cultured cells seems to suggest that the maturation gradient is controlled primarily by intrinsic factors.

\section{REFERENCES}

Baylor DA, Lamb TD, Yau K-W (1979) The membrane current of single rod outer segments. J Physiol (Lond) 288:589-611.

Brownell WE (1983) Observations on a motile response in isolated outer hair cells. In: Mechanism of hearing (Webster WR, Aitken LM, eds), pp 5-10. Clayton, Australia: Monash UP.

Brownell WE, Bader CR, Bertrand D, de Ribaupierre Y (1985) Evoked mechanical responses in isolated cochlear outer hair cells. Science 227:194-196.

Cajal, Sy (1919) Accion neurotropica de los epithelos (algun detalles sobre el mechanismo genetico de las ramificaciones nerviosas intra epitaliales, sensitivas y sensoriales). Studies on vertebrate neurogenesis (L Guth, translator). Springfield, IL: Charles C. Thomas.

Clark BA, Hallworth R, Evans BN (1990) Calibration of photodiode measurements of cell motion by a transmission optical lever method. Pflügers Arch 415:490-493.

Close R (1965) Effects of cross-union of motor nerves to fast and slow skeletal muscles. Nature 206:831-832.

Cole KS, Robertson D (1992) Early efferent innervation of the developing rat cochlea studied with a carbocyanine dye. Brain Res 575:223-230.

Dallos P (1992) The active cochlea. J Neurosci 12:4575-4585.

Dallos P, Hallworth R, Evans BN (1992) Stochastic theory of outer hair cell electromotility. In: Auditory physiology and perception (Cazals Y, Horner K, Demany L, eds), pp 35-43. Oxford: Pergamon.

Dallos P, He DZZ, Evans BN, Clark B (1993a) Dynamic characteristics of outer hair cell motility. In: Biophysics of hair cell sensory systems (Duifhuis H, Wit HP, van Dijk P, van Netten SM, eds), pp 167-174. Singapore: World Scientific.

Dallos P, Evans BN, Hallworth R (1993b) Theory of electrically driven shape changes of cochlear outer hair cells. J Neurophysiol 70:299-323.

Echteler SM (1992) Developmental segregation in the afferent projections to mammalian auditory hair cells. Proc Natl Acad Sci USA 89:6324-6327.

Echteler SM (1995) Structural correlates of frequency-place map development. Abstr Assoc Res Otolaryngol 1:67.

Evans BN, Hallworth R, Dallos P (1991) Outer hair cell electrmotility: the sensitivity and vulnerability of the DC component. Hear Res 52:288-304.

Furness DN, Richardson GP, Russell IJ (1989) Stereociliary bundle morphology in organotypic cultures of the mouse cochlea. Hear Res 38:95-110.

Haugland RP (1992) Fluorescent dyes for assessing vital cell functions. In: Molecular probes, handbook of fluorescent probes and research chemicals (Larison KD ed), pp 172-180. Eugene, OR: Molecular Probes, Inc.

He DZZ, Evans BN, Dallos P (1994) First appearance and development of electromotility in neonatal gerbil outer hair cells. Hear Res 78:77-90.

Holley MC, Ashmore JF (1990) Spectrin, actin and the structure of the cortical lattice in mammalian cochlear outer hair cells. J Cell Sci 96:283-291.

Horner KC, Serviere J, Granier-Deferre C (1987) Deoxyglucose demonstration of in-utero hearing in the guinea pig foetus. Hear Res 26:327-333.

Jörgensen JM, Flock $\AA$ (1976) Non-innervated sense organs of the lateral line: development in the regenerating tail of the salamander Ambystona mexicanum. J Neurocytol 5:33-41.

Kikuchi K, Hilding D (1965a) The development of the organ of Corti in the mouse. Acta Otolaryngol 60:207-222.

Kikuchi K, Hilding D (1965b) The defective organ of Corti in Shaker-1 mice. Acta Otolaryngol 60:288-303.

Knowlton VY (1967) Correlation of the development of membranes and bony labyrinths, acoustic ganglia, nerves and brain centers in the chick embryo. J Morphol 121:179-208.

Lefebvre PP, Leprince P, Weber T, Rigo J-M, Delree P, Moonen G (1990) Neuronotrophic effect of developing otic vesicle on cochleovestibular neurons: evidence for nerve growth factor involvement. Brain Res 507:254-260.

Lim DJ, Rueda J (1992) Structural development of the cochlea. In: Development of auditory and vestibular systems II (Romand R, ed), pp 33-55. New York: Elsevier Science.

Merchan-Perez A, Gil-Loyzaga P, Eybalin M, Fernandez Mateos P, Bartolome MV (1994) Choline-acetyltransferase-like immunoreactivity in the organ of Corti of the rat during postnatal development. Brain Res 82:29-34.

Mikaelian D, Ruben RJ (1964) Hearing degeneration in the Shaker-1 
mouse: correlation of physiological observation with behavioral response and with cochlear anatomy. Arch Otolaryngol 80:418-426.

Orr MF (1969) Histogenesis of sensory epithelium in reaggregates of dissociated embryonic chick otocysts. Dev Biol 17:39-44.

Perkins RE, Morest DK (1975) A study of cochlear innervation patterns in cats and rats with the Golgi method and Nomarkski Optics. J Comp Neurol 163:129-158.

Pirvola U, Lehtonen E, Ylikoski J (1991) Spatiotemporal development of cochlear innervation and hair cell differentiation in the rat. Hear Res 52:345-355.

Pujol R, Carlier E (1982) Cochlear synaptogensis alter sectioning the efferent bundle. Dev Brain Res 3:151-154.

Pujol R, Hilding DA (1973) Anatomy and physiology of the onset of auditory function. Acta Otolaryngol 76:1-10.

Pujol R, Carlier E, Devigne C (1978) Different patterns of cochlear innervation during the development of the kitten. J Comp Neurol 177:529-536.

Pujol R, Zajic G, Dulon D, Raphael Y, Altschuler RA, Schacht J (1991) First appearance and development of motile properties in outer hair cells isolated from guinea-pig cochlea. Hear Res 57:129-141.

Romand R (1983) Development of the cochlea. In: Development of auditory and vestibular systems (Romand R, ed), pp 47-85. New York: Academic.

Rubel EW (1978) Ontogeny of structure and function in the vertebrate auditory system. In: Handbook of sensory physiology, Vol 9 (Jacobson M, ed), pp 135-237. New York: Springer.

Russell IJ, Cody AR, Richardson GP (1986a) The responses of inner and outer hair cells in the basal turn of the guinea-pig cochlea and in the mouse cochlea grown in vitro. Hear Res 22:199-216.

Russell IJ, Richardson GP, Cody AR (1986b) Mechanosensitivity of mammalian auditory hair cells in vitro. Nature 321:517-519.

Schweitzer L, Lutz C, Hobbs M, Weaver SP (1996) Anatomical correlates of the passive properties underlying the developmental shift in the frequency map of the mammalian cochlea. Hear Res 97:84-94.

Sher A (1971) Embryonic and postnatal development of the inner ear of the mouse. Acta Otolaryngol (Stockh) 285:1-77.

Simmons DD, Manson-Gieseke L, Hendrix TW, McCarter S (1990) Reconstructions of efferent fibers in the postnatal hamster cochlea. Hear Res 49:127-140.

Sobkowicz HM (1992) The development of innervation in the organ of Corti. In: Development of auditory and vestibular system II (Romand $\mathrm{R}$, ed), pp 59-100. New York: Elsevier Science.

Sobkowicz HM, Emmerling MR (1989) Development of acetylcholinesterase-positive neuronal pathways in the cochlea of the mouse. J Neurocytol 18:209-224.

Sobkowicz HM, Bereman B, Rose JE (1975) Organotypic development of the organ of Corti in culture. J Neurocytol 4:543-572.

Sobkowicz HM, Rose JE, Scott GL, Holy JM (1984) The ultrastructure of the developing organ of Corti of the mouse in culture. In: Ultrastruc- tural altas of the inner ear (Friedmann I, Ballantyne J, eds), pp 61-97. London: Butterworths.

Sobkowicz HM, Rose JE, Scott GL, Levenick CV (1986) Distribution of synaptic ribbons in the developing organ of Corti. J Neurocytol 15:693-714.

Sobkowicz HM, Loftus JM, Slapnick SM (1993) Tissue culture of the organ of Corti. Acta Otolaryngol (Stockh) 502:3-36.

Souter M, Nevill G, Forge A (1995) Postnatal development of membrane specializations of gerbil outer hair cells. Hear Res 91:43-62.

Speidel CC (1947) Correlated studies of sensory organs and nerves of the lateral line in living frog tadpole. I. Regeneration of denervated organs. J Comp Neurol 87:29-55.

Speidel CC (1948) Correlated studies of sense organs and nerves of the lateral line in living frog tadpoles. II. The trophic influence of specific nerve supply as revealed by prolonged observations of denervated and reinnervated organs. Am J Anat 82:227-320.

Speidel CC (1964) In vivo studies of myelinated nerve fibers. Int Rev Cytol 16:173-195.

Spoendlin H (1973) The innervation of the cochlear receptor. In: Proceeding of a symposium on basic mechanisms in hearing (Zwicker E, Terhardt E, eds), pp 18-32. New York: Springer.

Spoendlin H (1978) The afferent innervation of the cochlea. In: Evoked electrical activity in the auditory nervous system (Naunton RF, Fernández C, eds), pp 21-39. New York: Academic.

Sugahara M (1964) Morphological studies on the membranous labyrinth cultured in vitro (in Japanese). Japan Otolaryngol 66:855-902.

Thornhill RA (1972) Development of the labyrinth of the lamprey. Proc R Soc Lond [Biol] 181:175-198.

Van de Water TR (1976) Effects of removal of the stato-acoustic ganglion complex upon the growing otocyst. Ann Otolaryngol Rhinol Laryngol 33[Suppl 85]:1-32.

Van de Water TR (1988) Tissue interactions and cell differentiation: neurone-sensory cell interaction during otic development. Development [Suppl] 103:185-193.

Van de Water TR, Ruben RJ (1971) Organ culture of the mammalian inner ear. Acta Otolaryngol (Stockh) 330:77-90.

Van de Water TR, Ruben RJ (1973) Quantification of the "in vitro" development of the mouse embryo inner ear. Ann Otolaryngol Rhinol Laryngol 82 [Suppl 4]:19-21.

Van de Water TR, Heywood P, Ruben RJ (1973) Development of sensory structures in organ cultures of the twelfth and thirteenth gestation day mouse embryo inner ears. Ann Otolaryngol Rhinol Laryngol 82 [Suppl 4]:1-18.

Van de Water TR, Galinovic-Schwartz V, Ruben RJ (1989) Determinants of ganglion-receptor cell interaction during development of the inner ear. Acta Otolaryngol (Stockh) 108:227-237.

Yamashita T, Vosteen K-H (1975) Tissue culture of the organ of Corti and the isolated hair cells from the newborn guinea pig. Acta Otolaryngol (Stockh) 330:77-90. 